\title{
Validação de método para determinação de ácidos graxos voláteis em efluentes de biorreatores anaeróbios por meio de cromatografia gasosa
}

\author{
Validation of method for determining volatile fatty acids in \\ effluents of anaerobic biorreators through gas chromatography
}

Data de entrada: $21 / 12 / 2017$

Data de aprovação: 04/01/2018

Roberta Milena Moura Rodrigues*/ Beatriz Susana Ovruski de Ceballos/ Wilton Silva Lopes

DOI: $10.4322 /$ dae.2019.009

\section{Resumo}

Processos biológicos secundários anaeróbios empregados para o tratamento de águas residuais têm se desenvolvido de forma acelerada a partir da metade do século XX e são atualmente utilizados na maioria das Estações de Tratamento de Esgotos (ETEs) ao redor do mundo. Lodos produzidos ao longo do tratamento são o principal subproduto e constituem um material semisólido que contém matéria orgânica, micro-organismos patogênicos, substâncias tóxicas e até metais pesados retirados da fase líquida. Entretanto, aplicando-se tratamento adequado, pode se transformar um resíduo problema em um produto com valor econômico: com tecnologias modernas e de baixo custo, podem ser reaproveitados materiais nele contido (nutrientes e metais pesados) e pelo seu potencial energético (produção de biogás - 70\% de metano). Os ácidos graxos voláteis (AGVs) são importantes intermediários da digestão anaeróbia, e sua taxa de produção determina em grande parte a taxa de produção de metano. O conhecimento da concentração de AGVs no lodo em tratamento permite acompanhar o desempenho do reator. $O$ método de cromatografia gasosa acoplada à espectrometria de massas (CG/EM) para determinação de AGVs se destaca de outros por ser eficiente e seletivo, permite obter informação estrutural, massa molar, entre outras vantagens. A validação de um método para sua detecção assegura a confiança dos resultados. No presente trabalho foi utilizado o cromatógrafo gasoso Thermo Scientific (TRACE 1300), e o detector foi um espectrômetro de massas Thermo Scientific (ISQ QD Single Quadrupole) com uma coluna de polaridade intermediária SPB- 624. Foram utilizados reagentes (analitos) de marca reconhecida, e testes prévios foram feitos para definir condições adequadas para o método (CG/EM). A validação do mesmo foi realizada seguindo as recomendações de INMETRO e ANVISA. Os resultados mostraram que a validação do método (CG/EM) para determinação de AGVs com a coluna escolhida e as melhores condições cromatográficas obtidas mostraram-se adequadas, atendendo aos parâmetros de validação: linearidade ( $r \geq 0,9843$ ), precisão (coeficientes de variação < 20\%), sensibilidade (coeficientes an-

\footnotetext{
Roberta Milena Moura Rodrigues - Graduada em Química Industrial pela UEPB. Mestre em Ciência e Tecnologia Ambiental pela UEPB. Beatriz Susana Ovruski de Ceballos - Graduada em Bioquímica pela Universidade Nacional de Tucumán. Mestre em Microbiologia e Imunologia pela Universidade Federal de São Paulo. Doutora em Ciências Biológicas (Microbiologia Ambiental) pela USP. Professora Ttitular da UEPB, Departamento de Ciências Biológicas, CCBS. Professor do quadro permanente do Programa de Pós Graduação em Ciência e Tecnologia Ambiental da UEPB.

Wilton Silva Lopes - Graduado em Química Industrial pela UEPB. Mestre em Desenvolvimento e Meio Ambiente pela UFPB. Doutor em Química pela UFPB. Pós-Doutorado na Escola de Engenharia de São Carlos da USP e na Delft University of Technology na Holanda. Professor Associado A (Dedicação Exclusiva) do Departamento de Engenharia Sanitária e Ambiental da UEPB.

*Endereço para correspondência: Rua Pedro de Azevedo Cruz, 27 A, centro, Serra Redonda, Paraíba. Telefone: (83) 98717-4209. E-mail: robertamilena_rmahotmail.com.
} 
gulares $\geq 238218)$, limite de detecção $\left(0,030 \mathrm{mg} \cdot \mathrm{L}-1\right.$ - 0,848 $\left.\mathrm{mg} \cdot \mathrm{L}^{-1}\right)$, limite de quantificação $\left(0,120 \mathrm{mg} \cdot \mathrm{L}^{-1}\right.$ - 2,827 mg. $\left.\mathrm{L}^{-1}\right)$, exatidão (100\% - 110\% - concentrações maiores). Aplicado em matrizes reais, o método se mostrou satisfatório porque os tempos de retenção foram muito semelhantes aos dos padrões utilizados.

Palavras-chave: Digestão anaeróbia. Espectrometria de massas. Metano.

\section{Abstract}

Secondary biological anaerobic processes used for wastewater treatment have developed rapidly since the mid20th century and are currently used in most Sewage Treatment Plants (ETES) around the world. Sludge produced throughout the treatment is the main byproduct and is a semi-solid material containing organic matter, pathogenic microorganisms, toxic substances and even heavy metals withdrawn from the liquid phase. However, by applying appropriate treatment, it can transform itself from a problem residue into a product with economic value: modern and low-cost technologies can be reused in the material (nutrients and heavy metals) and its energy potential (biogas production - 70\% methane). Volatile fatty acids (AGVs) are important intermediates of anaerobic digestion and their rate of production largely determines the rate of methane production. The knowledge of the concentration of VFAs in the sludge under treatment allows monitoring the performance of the reactor. The gas chromatography coupled to mass spectrometry (GC / MS), for the determination of VFAs, stands out from others for being efficient and selective, and allows structural information, molar mass, among other advantages. The validation of a method for its detection ensures the reliability of the results. In the present work, the Thermo Scientific gas chromatograph (TRACE 1300) was used and the detector was a Thermo Scientific mass spectrometer (ISQ QD - Single Quadrupole) with an SPB-624 intermediate polarity column. Recognized brand reagents And previous tests were done to define suitable conditions for the method (CG / MS). Validation was done following the recommendations of INMETRO and ANVISA. The results showed that the validation of the method (GC / MS) for determination of VFAs with the chosen column and the best chromatographic conditions obtained were adequate, taking into account the validation parameters: linearity $(r \geq 0,9843)$, precision Coefficients of variation $<20 \%$ ), sensitivity (angular coefficients $\geq 238218$ ), limit of detection (0.030 mg.L-1 - $0.848 \mathrm{mg} . \mathrm{L}-1$ ), limit of quantification (0.120 mg.L-1 - $2.827 \mathrm{mg} . \mathrm{L}$-1), accuracy (100\% - 110\% - higher concentrations). Applied to real matrices, the method proved to be satisfactory because the retention times were very similar to the patterns used. Keywords: Anaerobic digestion. Mass spectrometry. Methane.

\section{INTRODUÇÃO}

Os processos biológicos secundários empregados para o tratamento de águas residuais têm se desenvolvido de forma acelerada a partir da metade do século XX e são atualmente utilizados na maioria das Estações de Tratamento de Esgotos (ETEs) ao redor do mundo.

Durante o tratamento dos esgotos são produzidos lodos que se decantam no tanque de sedimentação primário por deposição por gravidade das partículas sólidas; já nos reatores biológicos de tratamento secundários a produção de lodos é mais abundante, principalmente se o processo for aeróbio, e se depositam no decantador secundário; também são gerados no tratamento terciário (METCALF, EDDY, 2003).

Alem Sobrinho (2001) cita que a produção de esgoto doméstico no Brasil varia entre 80 a 200 litros/ hab.dia e cada habitante produziria cerca de $150 \mathrm{~g} /$ dia de lodo centrifugado, totalizando uma produção média em torno de 150 a 220 mil toneladas de matéria seca por ano. Para Andreoli et al. (2001), no Brasil, aumentos na coleta dos esgotos realmente gerados poderiam incrementar em até 4 vezes a produção de lodos. Cálculos de Soares (2004), que 
consideraram o tratamento de somente $30 \%$ dos esgotos urbanos produzidos, mostraram uma geração de lodos superior a 400.000 mil toneladas/ ano. O lodo das estações de tratamento de esgoto doméstico é um material pastoso, semi-sólido, rico em água (até 98\%) e com teor de sólidos na ordem de 1 a 2 e até de $5 \%$, sendo estes principalmente orgânicos de composição complexa e putrescível (proteínas, carboidratos, lipídeos, ácidos nucléicos, entre outros), possui também fosfatos, nitratos, nitritos e diversas formas de enxofre, além de ferro, magnésio, cálcio, entre outros componentes (MIKI et al., 2006). A matéria orgânica constitui de 59 a $88 \%$ dos sólidos totais, sendo aproximadamente 50 a 55\% de carbono, 25 a 30\% de oxigênio, 10 a15\% de nitrogênio, 6 a10\% de hidrogênio, 1 a $3 \%$ de fósforo e 0,5 a 1,5\% de enxofre (TIAGY; LO, 2013). Contém ainda detergentes e algumas substâncias de difícil degradação, como compostos fenólicos, usados de intermediários ou aditivos na produção dos detergentes e emulsificantes, entre outras muitas e diversas moléculas (CORVINI et al., 2006), microrganismos patogênicos (vírus, bactérias protozoários, helmintos e fungos) e até a metais pesado como cádmio, cobre, cromo, chumbo, níquel, manganês, mercúrio e zinco embora em baixas concentrações (CHAGAS, 2000). Os microrganismos patogênicos e as substâncias xenobióticas e recalcitrantes tornam os lodos brutos dos esgotos resíduos perigosos e um problema de saúde pública e ambiental quando descarregados no solo e na água sem tratamento prévio, por veicularem doenças infecciosas e afetarem a qualidade das águas e dos solos alterando a microbiota e em consequência as cadeias e as teias alimentares (JONSSON, MAIA, 2007).

O lodo é o principal subproduto do tratamento das águas residuais e deve ser tratado para decidir seu destino adequado, sem causar impactos à saúde pública e ao meio ambiente. Sua disposição sanitária e/ou a sua utilização na agricultura e em empreendimentos florestais é um dos mais importantes problemas associados ao projeto e ao gerenciamento das estações de tratamento de esgotos; problema que aumenta com o crescimento populacional e a consequente maior produção de esgotos e de lodos das ETEs, na medida em que as redes de coleta de águas residuais são ampliadas e novas estações de tratamento de esgoto são construídas e entram em funcionamento. A correta gestão do lodo é questão relevante de saúde pública, ambiental e sanitária que as empresas de saneamento devem enfrentar e respeitar as disposições da legislação ambiental: a Lei No 12. 305/2010 que institui a Política Nacional de Resíduos Sólidos no Brasil assim como Resolução Conama No 430 do 13/05/2011, que complementa e altera a Resolução n 357/2005 e dispõe sobre as condições adequadas para o descarte de efluentes finais de ETEs.

Lettinga et al. (2000) enfatizam que muitos dos resíduos produzidos pelas sociedades humanas podem ser materiais úteis para a recuperação $\mathrm{e}$ que para reusar subprodutos como nutrientes, metais, a água que os compõe e a energia contida na matéria orgânica não totalmente degradada, para atingir esses objetivos de proteção ambiental e conservação dos recursos, diversas técnicas já estão disponíveis. Efetivamente, os lodos dos esgotos são fontes valiosas de macronutrientes para a agricultura e reflorestamento, como nitrogênio, fósforo, enxofre e cálcio entre outros, que podem ser recuperados assim como os metais pesados ali contidos. Os lodos são muito valorizados como fonte de energia, devido à possibilidade de recuperar a energia dos resíduos orgânicos por meio da biodegradação microbiana com produção de biogás, em especial metano. Este é liberado na fermentação metanogênica sob condições controladas de $\mathrm{pH}$, temperatura e substratos apropriados e portanto, para a recuperação da energia na forma de biogás deve-se preferir, na etapa de estabilização, a digestão anaeróbia (VAN HAANDEL; LETTINGA, 1994).

Com essa abordagem e aplicando-se tratamento anaeróbio, o lodo transforma-se de um resíduo 
problema em um produto com valor econômico que com tecnologias modernas e de baixo custo pode ser bem mais valorizado pelo reaproveitamento dos materiais nele contidos (nutrientes e metais pesados) e pelo seu potencial energético (gás metano). Dentre as diversas tecnologias disponíveis, a digestão anaeróbia convencional (DA) é uma excelente opção para o tratamento do lodo derivado do esgoto sanitário. Durante o processo são reduzidas as concentrações dos microrganismos patogênicos (e estes podem até ser eliminados), estabilizam-se total ou parcialmente as substâncias orgânicas putrescíveis presentes no lodo fresco, reduz-se o volume do lodo por meio de liquefação, gaseificação e adensamento pela diminuição de seu conteúdo em água. A digestão anaeróbia ou fermentação permite também dotar o lodo de características favoráveis para seu uso em solos e outras finalidades após estabilizado e recuperados os metais pesados e a energia.

Os processos da digestão anaeróbia são geralmente explicados como a sequência de quatro fases bioquímicas correspondentes aos metabolismos dos grupos microbianos envolvidos e predominantes em cada uma delas e denominadas fases de hidrólise, acidogênese, acetogênese e metanogênese (VAN HAANDEL; LETTINGA, 1994; CHERNICHIARO,1997). Em cada uma dessas fases, micro-organismos específicos metabolizam os substratos orgânicos, seja nos lodos, nos esgotos ou de qualquer ambiente com material orgânico putrescível passível de biodegração ou estabilização por microrganismos heterótrofos fermentativos. Na digestão anaeróbia com metanogêneses, esses grupos de bactérias e arqueias agem sucessivamente e sintroficamente e são denominadas, respectivamente, bactérias hidrolíticas, acidogênicas, acetogênicoas e arqueias metanogênicas (VAN HAANDEL; LETTINGA, 1994; MADIGAN, et al., 2016). Na fase acidogênica são produzidos, a partir das macromoléculas orgânicas hidrolisadas na fase anterior, ácidos graxos voláteis (AGVs) de baixo peso molecular, que são os principais intermediários das etapas seguintes da digestão anaeróbia fermentativa dos compostos orgânico dos lodos e dos esgotos e, portanto, da produção de biogás. Sua taxa de produção determina a taxa de produção de metano (CHERNICHIARO, 1997; SAWYER; MCCARTHY, 1978). Mudanças ambientais e/ou operacionais podem causar o desequilíbrio da taxa de produção e consumo dos AGVs, por isso, o monitoramento da sua concentração é fundamental para evitar problemas operacionais; o acúmulo desses ácidos pode ter um efeito negativo sobre a digestão anaeróbia, se a capacidade de tamponação for extrapolada e o pH descer para níveis desfavoráveis, por sua vez, uma taxa baixa de formação também freia o resto do processo pela falta de substratos para as bactérias das etapas subsequentes (CHERNICHIARO, 1997; LEITÃO et al., 2006).

Diversos métodos foram desenvolvidos para a determinação de ácidos graxos voláteis; dentre eles destaca-se a cromatografia gasosa, utilizando como detector um espectrômetro de massas, que oferece alta eficiência na detecção de baixas concentrações. A validação adequada da metodologia assegura a qualidade metrológica dos ensaios e a confiabilidade técnica dos resultados obtidos. 0 trabalho tem por objetivo validar um método de cromatografia gasosa acoplada a um espectrômetro de massa (CG/ EM) para a determinação de ácidos graxos voláteis, considerando sua importância como intermediários essenciais na digestão anaeróbia e precursores da metanogênese, processo que permite recuperar parte importante da energia contida nos resíduos orgânicos na forma de biogás.

\section{METODOLOGIA}

\subsection{Local das análises}

a pesquisa foi realizada no laboratório de Química Sanitária e Ambiental (LAQUISA) da Estação Experimental de Tratamento Biológico de Esgoto Sanitário (EXTRABES), situada na cidade de Campina Grande/PB (070 14' 22"' S e 35 53'05' W), 
em área pertencente à Companhia de Água e Esgoto de Campina Grande - CAGEPA, cedida em sistema de comodato à Universidade Estadual da Paraíba (UEPB).

\subsection{Escolha dos reagentes e padrões}

Os ácidos graxos voláteis escolhidos foram ácido acético, ácido propiônico, ácido isobutírico, ácido butírico, ácido isovalérico, ácido valérico. Para preparação dos analitos padrões foram escolhidos ácidos P.A. da marca Sigma Aldrich que são apresentados na tabela 1 .

Tabela 1- Pureza, molaridade e concentração comum dos ácidos graxos voláteis (AGVs).

\begin{tabular}{|c|c|c|c|}
\hline $\begin{array}{c}\text { Ácidos } \\
\text { (Sigma } \\
\text { Aldrich) }\end{array}$ & $\begin{array}{c}\text { Pureza } \\
\text { (\%) }\end{array}$ & $\begin{array}{c}\text { Molaridade } \\
\text { (mol/L) }\end{array}$ & $\begin{array}{c}\text { Concentração } \\
\text { Comum } \\
\text { (g/L) }\end{array}$ \\
\hline Ácido Acético & 99,7 & 17,43 & 1046,85 \\
\hline $\begin{array}{c}\text { Ácido } \\
\text { Propiônico }\end{array}$ & 99,0 & 13,23 & 980,10 \\
\hline $\begin{array}{c}\text { Ácido } \\
\text { Isobutírico }\end{array}$ & 99,5 & 10,95 & 965,15 \\
\hline Ácido Butírico & 99,0 & 10,78 & 950,40 \\
\hline $\begin{array}{c}\text { Ácido } \\
\text { Isovalérico }\end{array}$ & 99,0 & 8,97 & 915,75 \\
\hline Ácido Valérico & 99,0 & 9,01 & 920,70 \\
\hline
\end{tabular}

\subsection{Preparação das soluções padrões de ácidos graxos voláteis (AGVs)}

No preparo das soluções foram utilizados água Milli Q (para as soluções estoque de $500 \mathrm{mg}^{\mathrm{L} \mathrm{L}^{-1} \text { ) e }}$ metanol P.A. (para as diluições). Preparou-se uma solução estoque de $500 \mathrm{mg} . \mathrm{L}^{-1}$ para cada ácido graxo volátil (ácido acético, ácido propiônico, ácido isobutírico, ácido butírico, ácido isovalérico e ácido valérico) e uma solução estoque de $500 \mathrm{mg}^{-1} \mathrm{La}^{-1}$ mistura dos seis ácidos; a seguir se realizaram diluições das soluções padrões de cada ácido, até atingirem as concentrações de $0,5 \mathrm{mg} \cdot \mathrm{L}^{-1}, 1 \mathrm{mg} \cdot \mathrm{L}^{-1}, 2,5$ $\mathrm{mg} \cdot \mathrm{L}-1,5 \mathrm{mg} \cdot \mathrm{L}^{-1}$, as soluções padrões individuais de cada ácido foram injetadas sequencialmente no cromatógrafo gasoso para obter o cromatograma desses padrões que permitem encontrar as melho- res condições para a elaboração do método e para a determinação dos tempos de retenção de cada um desses compostos. Em seguida foram preparadas diluições a partir da solução estoque de 500 $\mathrm{mg} . \mathrm{L}^{-1}$ composta pela mistura dos seis ácidos para montar a faixa de trabalho a ser utilizada. As concentrações da faixa de trabalho foram: $0,5 \mathrm{mg} \cdot \mathrm{L}^{-1}$, $0,7 \mathrm{mg} \cdot \mathrm{L}^{-1}, 1 \mathrm{mg} \cdot \mathrm{L}^{-1}, 1,5 \mathrm{mg} \cdot \mathrm{L}^{-1}, 2 \mathrm{mg} \cdot \mathrm{L}^{-1}, 2,5 \mathrm{mg} \cdot \mathrm{L}^{-1}$, $3 \mathrm{mg} \cdot \mathrm{L}^{-1}, 4 \mathrm{mg} \cdot \mathrm{L}^{-1}$ e $5 \mathrm{mg} \cdot \mathrm{L}^{-1}$. Posteriormente cada concentração que contém a mistura dos seis ácidos foi injetada seis vezes no cromatógrafo para analisar a separação dos picos do cromatograma para cada um dos AGVs, os tempos de retenção de cada um, montar a curva de calibração e se analisar as melhores condições do método.

\subsection{Cromatografia Gasosa / Espectrometria de Massas}

O cromatógrafo gasoso utilizado é da marca Thermo Scientific (TRACE 1300) e o detector é um espectrômetro de massas Thermo Scientific (ISQ QD - Single Quadrupole). As condições cromatográficas foram estabelecidas com base em dados da literatura e injeções testes para obter as melhores condições cromatográficas, visando maior sensibilidade na identificação dos AGVs selecionados. A coluna utilizada no cromatógrafo gasoso é SPB - 624 Capillary GC column, com fase estacionária (6\% cianopropilfenil, 94\% dimetilpolisiloxano) que possui polaridade intermediária. Foram estabelecidas as seguintes variáveis: tamanho da coluna cromatográfica (30 $\mathrm{m} \times 0,25 \mathrm{~mm}$ ), espessura do filme $(1,4 \mu \mathrm{m})$, volume de injeção de $1 \mu \mathrm{l}$, temperatura do injetor $\left(170^{\circ} \mathrm{C}\right)$, modo de injeção (splitless), velocidade linear do gás de arraste (gás Hélio - $1 \mathrm{~mL} . \mathrm{min}^{-1}$ ), temperatura da interface $\left(250^{\circ} \mathrm{C}\right.$ ), temperatura da fonte de ionização (impacto de elétrons) do espectrômetro de massa $\left(230^{\circ} \mathrm{C}\right)$, tempo de corte do solvente (4 minutos). Foram testadas algumas rampas de temperatura do forno, e as melhores condições encontradas foram de $35^{\circ} \mathrm{C}$, com tempo de espera de 1 minuto, 
seguido de aumentos de temperatura na taxa de $20^{\circ} \mathrm{C} \cdot \mathrm{min}^{-1}$ até $100^{\circ} \mathrm{C}$ com tempo de espera também de 1 minuto e continuando com taxa de $50^{\circ} \mathrm{C}$. $\min ^{-1}$ até atingir $200^{\circ} \mathrm{C}$ com tempo de espera de 3 minutos. Após escolhida a melhor condição cromatográfica para realização das injeções, procedeu-se à validação do método.

\subsection{Validação de método}

A validação da metodologia de análise de AGVs foi realizada utilizando critérios conforme Resolução ANVISA RE n 899, de 29 de maio de 2003 e documento INMETRO DOQCGCRE-008, de 2016.

Para a validação de um método analítico é fundamental o perfeito controle da qualidade dos reagentes a serem usados: fornecedor, marca, qualidade (grau de pureza) da água ou do diluente a ser usado, entre outros. Destaca-se que os reagentes devem ser grau P.A. (Para Análises) e as soluções preparadas com água deionizada ultrapura. A seguir, deve haver controle acurado da exatidão das concentrações dos reagentes, devem-se conhecer os equipamentos a serem utilizados e seu funcionamento, os pontos críticos do aparato e da técnica, e as temperaturas envolvidas no processo que devem ser controladas ao longo de toda a operação. Ainda, para a avaliação correta e segura dos critérios estabelecidos pela ANVISA e INMETRO, foram empregadas soluções com diferentes concentrações, em ordem crescente, e as análises para cada uma dessas concentrações foram feitas no mínimo com cinco repetições. Sem esses cuidados cada um dos critérios de validação (linearidade, precisão, sensibilidade, limite de deteç̧ão, limite de quantificação e exatidão) não seria corretamente estabelecido.

Linearidade: Foram utilizadas soluções padrões nas concentrações escolhidas para a faixa de trabalho, foi feita a análise de regressão por mínimos quadrados e a correlação linear foi obtida por meio do $\mathrm{R}^{2}$. Foram elaborados os gráficos de resíduos para cada ácido e realizado o test $\mathrm{F}$ ( $\mathrm{F}$-Snedecor) na análise da variância (ANOVA) da regressão.

Precisão: Foi obtida com base na repetitividade. Foram feitas cinco repetições de cada concentração de cada ácido, pelo mesmo analista e nas mesmas condições operacionais, contemplando o intervalo linear do método, ou seja, concentrações baixa, média e alta. Após as repetições foram calculados os coeficientes de variação de cada ácido para as três concentrações utilizadas.

Sensibilidade: Foi determinada por intermédio da inclinação da curva analítica, uma vez que quanto maior a absortividade da substância, maior o coeficiente angular e mais sensível é o método.

Limite de detecção e quantificação: Foi preparada uma solução estoque a partir dos seis ácidos puros e a seguir se procedeu a diluir essa solução até se aproximar do suposto limite de quantificação. Após leitura de cada uma dessas diluições no cromatógrafo sob as condições previamente definidas, foram preparadas três curvas de calibração de cada ácido para obter seus coeficientes lineares e calcular o desvio padrão desses coeficientes, os valores dos desvios padrões obtidos divididos pelos coeficientes angulares das curvas de calibração de cada ácido, multiplicado por três é o limite de detecção e o mesmo valor multiplicado por dez é o limite de quantificação. O limite de detecção também foi calculado multiplicando por três o ruído da linha de base; nesse caso, o limite de quantificação foi aproximadamente 10 vezes maior que esse ruído.

Exatidão: A exatidão foi calculada como a diferença porcentual entre as médias e o valor verdadeiro aceito, acrescida dos intervalos de confiança. A exatidão do método foi determinada após o estabelecimento da linearidade, do intervalo linear, sendo verificada a partir de no mínimo nove determinações contemplando o intervalo linear do procedimento, ou seja, três concentrações (baixa, média e alta), com seis réplicas cada uma. 


\subsection{Amostras para aplicação do método CG/EM para detecção e quantificação de AGVs em matrizes reais}

Para avaliar a eficácia do método de recuperação dos AGVs em matrizes reais foram utilizadas amostras de lodos e permeado obtidos de reatores anaeróbios em funcionamento na EXTRABES (um biorreator anaeróbio de membrana dinâmica - BRAnMD, e dois digestores anaeróbios convencionais - DAC1 e DAC2) e amostras de lodo originado de resíduos sólidos de um reator em batelada. Os sistemas experimentais BRAnMD e DAC1 e DAC2 foram alimentados com lodo aeróbio de excesso de um sistema de lodo ativado que por sua vez recebia esgoto doméstico. Este era aduzido do interceptor leste do sistema de esgotamento sanitário da Companhia de Águas e Esgotos da Paraíba (CAGEPA) da cidade de Campina Grande, que passa pelas dependências da Estação Experimental de Tratamento Biológico de Esgoto Sanitário (EXTRABES) e efluente (resíduos sólidos) obtidos de um reator em batelada, alimentado em batelada, de resíduos obtidos na Empresa Paraibana de Abastecimento e Serviços Agrícolas (EMPASA). Volumes de $100 \mathrm{~mL}$ das amostras das matrizes reais foram coletados em béqueres e transferidos para garrafas de polietileno que foram preservadas na geladeira a $4{ }^{\circ} \mathrm{C}$ até o momento de uso. Para realizar as análises, $2 \mathrm{~g}$ das amostras eram pesadas em um tubo eppendorf, em seguida foram centrifugadas (centrífuga refrigerada Excelsa 4, mod. 280R-Fanem) durante 15 min, 12.000 rpm. Após centrifugação, o sobrenadante das amostras foi filtrado em microfiltro de fibra de vidro (GF-2, diâmetro $47 \mathrm{~mm}$ ), tamanho de poro $0,45 \mu \mathrm{m}$ (GF-2) e a seguir $5 \mu \mathrm{L}$ do filtrado das amostras provenientes de lodo de esgoto foram diluídos quarenta vezes em metanol P.A. e $5 \mu \mathrm{L}$ do filtrado das amostras provenientes de efluentes de resíduos sólidos foram diluídos cinquenta vezes em metanol P.A.

\section{RESULTADOS E DISCUSSÃO}

\subsection{Parâmetros de validação}

A seguir foram calculados os parâmetros de validação para CG/EM seguindo as recomendações ANVISA (2003), INMETRO (2016).

\subsubsection{Linearidade}

Os coeficientes de correlação linear foram obtidos a partir da curva de calibração de cada ácido, utilizando os coeficientes de determinação $\left(R^{2}\right)$. A tabela 2 mostra os resultados obtidos, onde se verifica forte correlação.

Tabela 2- Coeficientes de correlação linear dos ácidos graxos voláteis em estudo.

\begin{tabular}{|c|c|}
\hline Analito & Coeficiente de correlação linear (r) \\
\hline Ácido acético & 0,9917 \\
\hline Ácido propiônico & 0,9905 \\
\hline Ácido isobutírico & 0,9848 \\
\hline Ácido butírico & 0,9843 \\
\hline Ácido isovalérico & 0,9868 \\
\hline Ácido valérico & 0,9871 \\
\hline
\end{tabular}

A ANVISA (2003) considera para o coeficiente de correlação linear o valor igual a 0,99. Dos seis ácidos analisados, quatro (acético, propiônico, isovalérico, valérico) atenderam ao padrão, tendo em vista que os valores dos coeficientes de correlação linear dos ácidos isovalérico e valérico, se arredondados para duas casas decimais, correspondem a 0,99, enquanto os ácidos isobutírico e butírico tiveram coeficientes bem próximos a esse valor.

De acordo com INMETRO (2016), para comprovar a linearidade deve-se mostrar o gráfico dos resíduos para garantir que eles sejam aleatórios e também avaliar a linearidade com aplicação do teste $\mathrm{F}$ (também conhecido como F-Snedecor) na análise da variância (ANOVA) da regressão. Os resíduos foram aleatórios, comprovando que o modelo linear é adequado. A tabela 3 mostra os valores de $\mathrm{F}$ tabelado e de $\mathrm{F}$ calculado. 
Tabela 3 - Valores de F calculado e F tabelado para cada ácido.

\begin{tabular}{|c|c|c|}
\hline Analito & $\mathbf{F}$ (calculado) & $\mathbf{F}$ (tabelado) \\
\hline Ácido acético & 359,24 & 5,99 \\
\hline Ácido propiônico & 260,86 & 6,61 \\
\hline Ácido isobutírico & 165,41 & 6,61 \\
\hline Ácido butírico & 140,08 & 6,61 \\
\hline Ácido isovalérico & 120,04 & 7,71 \\
\hline Ácido valérico & 120,87 & 7,71 \\
\hline
\end{tabular}

Como o valor de $\mathrm{F}$ calculado é maior que o valor de $\mathrm{F}$ tabelado, deve-se rejeitar a hipótese nula, que diz: o coeficiente angular é igual a zero e não há correlação linear significativa entre x e y aceitando-se a hipótese alternativa que diz que o coeficiente angular é diferente de zero, demonstrando assim que há correlação linear significativa entre x y (MAGALHÃES, 2004).

Os valores do presente trabalho são coincidentes com os obtidos por Mulat e Feilberg (2015), que utilizaram cromatografia gasosa acoplada a um espectrômetro de massas (CG/EM) com coluna de alta polaridade (HP-INNOWax) e validaram o método para determinação do enriquecimento de isótopos de carbono e concentração de ácidos graxos de cadeia curta não derivatizados por injeção em solução aquosa direta de amostras de digestor de biogás (os ácidos analisados foram acético, propiônico, isobutírico, butírico, isovalérico, valérico), e sua faixa de trabalho foi de $0,5 \mathrm{mmol} / \mathrm{L}$ a $10 \mathrm{mmol} / \mathrm{L}$ (concentrações se convertidas em mg. $\mathrm{L}^{-1}$, será muito superior a faixa de trabalho do respectivo trabaIho), foi obtida boa linearidade para todos os ácidos com coeficientes de regressão superiores a 0,9978. Se comparada à faixa de trabalho e o tipo de coluna utilizada com o trabalho em estudo, os resultados aqui obtidos se mostram satisfatórios.
Fiorini et al. (2016), para analisar ácidos graxos voláteis de cadeia curta (acético, propiônico, isobutírico, butírico, isovalérico, valérico e ácido capróico) em fezes de ratos, utilizaram um método quantitativo, cromatografia gasosa com detector de ionização de chama, headspace e micro extração em fase sólida. As curvas de calibração foram construídas com concentrações de 0,01 até 315 mg.L ${ }^{-1}$; o menor coeficiente de determinação obtido foi o do ácido butírico :0,9956; para todos os outros ácidos os valores foram maiores, sendo bem próximos dos valores obtidos no presente trabalho, que utilizou injeção direta.

Amer et al. (2013), em seu novo método para a quantificação de ácidos graxos voláteis individuais no leite, usando derivatização e cromatografia gasosa - espectrometria de massas, utilizando uma coluna HP-5MS, revestida com poliimida, a curva de calibração é feita com concentrações $0,5 \mathrm{mg} \cdot \mathrm{L}^{-1}$ - $50 \mathrm{mg} \cdot \mathrm{L}^{-1}$, o valor obtido para o coeficiente de determinação do ácido butírico foi de 0,9994 , valor próximo ao obtido no presente trabalho. Deve-se levar em consideração que as concentrações utilizadas foram maiores do que as utilizadas no presente trabalho e também foi utilizada derivatização.

\subsubsection{Precisão}

Nas tabelas 4, 5 e 6 são apresentados os respectivos valores de média, desvio padrão e coeficiente de variação (foi utilizado o software Microsoft Excel para realização dos cálculos), visando avaliar a precisão do método para os seis ácidos. 
Tabela 4 - Valores médios, desvio padrão e coeficiente de variação dos seis AGVs utilizados, na concentração de 0,5 mg. $\mathrm{L}^{-1}$.

\begin{tabular}{|c|c|c|c|c|c|c|}
\hline Amostras & Acético & Propiônico & Isobutírico & Butírico & Isovalérico & Valérico \\
\hline 1 & 225492 & 182496 & 107569 & 80982 & 3487520 & 611847 \\
\hline 2 & 279566 & 225396 & 97846 & 76951 & 3480439 & 581627 \\
\hline 3 & 234093 & 199088 & 120997 & 59624 & 3747580 & 568936 \\
\hline 4 & 253589 & 212503 & 89237 & 68252 & 3841573 & 537444 \\
\hline 5 & 223459 & 144336 & 125814 & 60597 & 3371767 & 416651 \\
\hline$M^{*}$ & 243240 & 192764 & 108293 & 69281 & 3585776 & 543301 \\
\hline $\mathrm{DP}^{* * * *}$ & 23540,34 & 31405,38 & 15339,22 & 9558,553 & 198848,4 & 75662,14 \\
\hline CV\% & 9,7 & 16,3 & 14,2 & 13,8 & 5,5 & 13,9 \\
\hline
\end{tabular}

"M = Média; ** DP = Desvio padrão; **** CV = Coeficiente de variação

Tabela 5 - Valores médios, desvio padrão e coeficiente de variação dos seis AGVs utilizados, na concentração de 2 mg.L-1.

\begin{tabular}{|c|c|c|c|c|c|c|}
\hline Amostras & Acético & Propiônico & Isobutírico & Butírico & Isovalérico & Valérico \\
\hline 1 & 3946274 & 2476769 & 765437 & 378013 & 16703227 & 9539301 \\
\hline 2 & 3882986 & 2081377 & 711247 & 422223 & 17135654 & 7375750 \\
\hline 3 & 4466806 & 2466928 & 803071 & 499229 & 18676994 & 10467575 \\
\hline 4 & 4301508 & 2381786 & 824292 & 453807 & 20653447 & 9496111 \\
\hline 5 & 4223162 & 2384480 & 748859 & 441162 & 18793665 & 9142779 \\
\hline$M^{*}$ & 4164147 & 2358268 & 770581 & 438887 & 18392597 & 9204303 \\
\hline $\mathrm{DP}^{* * * *}$ & 245190,6 & 161057,8 & 44607,25 & 44306,53 & 1564214 & 1133647 \\
\hline $\mathrm{CV} \%^{\text {**o; }}$ & 5,9 & 6,8 & 5,8 & 10,1 & 8,5 & 12,3 \\
\hline
\end{tabular}

"M = Média; **"DP = Desvio padrão; ****"CV = Coeficiente de variação

Tabela 6 - Valores médios, desvio padrão e coeficiente de variação dos seis AGVs utilizado, na concentração de 5 mg. $\mathrm{L}^{-1}$.

\begin{tabular}{|c|c|c|c|c|c|c|}
\hline Amostras & Acético & Propiônico & Isobutírico & Butírico & Isovalérico & Valérico \\
\hline 1 & 15661804 & 8194006 & 2450074 & 1479678 & 47664484 & 33708752 \\
\hline 2 & 15578629 & 8266889 & 2432480 & 1482185 & 58499677 & 31309265 \\
\hline 3 & 15130743 & 7764369 & 2364383 & 1403060 & 54579427 & 33751743 \\
\hline 4 & 14965686 & 7617104 & 2250295 & 1307029 & 53539391 & 31355316 \\
\hline 5 & 13925048 & 7693417 & 2279442 & 1397782 & 51829220 & 30413355 \\
\hline$M^{*}$ & 15052382 & 7907157 & 2355335 & 1413947 & 53222440 & 32107686 \\
\hline $\mathrm{DP}^{* * * *}$ & 695138,5 & 300787,6 & 89165,28 & 72090,51 & 3956736 & 1528122 \\
\hline CV\% & 4,6 & 3,8 & 3,8 & 5,1 & 7,4 & 4,7 \\
\hline
\end{tabular}

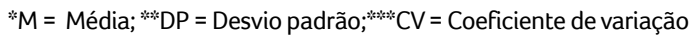

O INMETRO (2016) utiliza os critérios de aceitação sugeridos pela AOAC (2012), que aceitam o desvio padrão relativo ou coeficiente de variação de $11 \%$ para concentrações superiores a $0,1 \mathrm{mg} \cdot \mathrm{L}^{-1}$ até $1 \mathrm{mg} \cdot \mathrm{L}^{-1}$ e valores de 7,3\% para concentrações maiores que $1 \mathrm{mg} \cdot \mathrm{L}^{-1}$ até $10 \mathrm{mg} \cdot \mathrm{L}^{-1}$. O INMETRO (2016) também utiliza as sugestões de Eurachem (2014), considerando a dificuldade de estimar um desvio padrão confiável a partir de poucas repetições; nesse caso é admissível que os valores calculados a partir de vários pequenos grupos de repetições possam ser agrupados para obter estimativas com números suficientes de graus de liberdade. A tabela 7 mostra o valor médio dos desvios padrões relativos ou coeficientes de variação. 
Tabela 7 - Média dos coeficientes de variação para cada ácido.

\begin{tabular}{|c|c|c|c|c|c|c|}
\hline Amostras & Acético & Propiônico & Isobutírico & Butírico & Isovalérico & Valérico \\
\hline Concentração 0,5 mg. $\mathrm{L}^{-1}$ & 9,7 & 16,3 & 14,2 & 13,8 & 5,5 & 13,9 \\
\hline Concentração 2 mg. $\mathrm{L}^{-1}$ & 5,9 & 6,8 & 5,8 & 10,1 & 8,5 & 12,3 \\
\hline Concentração 5 mg.L-1 & 4,6 & 3,8 & 3,8 & 5,1 & 7,4 & 4,7 \\
\hline MCV\%* & 6,7 & 8,9 & 7,9 & 9,7 & 7,1 & 10,3 \\
\hline
\end{tabular}

*MCV= Média dos coeficientes de variação.

Sendo assim, analisando a média dos coeficientes de variação, apenas o ácido acético e o isovalérico obedecem ao intervalo aceito de 7,3. Já analisando as concentrações individuais, o método apresentou boa precisão apenas para a concentração de $5 \mathrm{mg} \cdot \mathrm{L}^{-1}$. A ANVISA (2003) aceita o coeficiente de variação de até $5 \%$ para métodos analíticos, porém para matrizes biológicas aceita o coeficiente de variação até $20 \%$, considerando a segunda opção os valores das três concentrações são aceitos por estarem inclusos no intervalo. $\mathrm{O}$ que fica claro no método é que ele apresentou melhor precisão para a concentração mais alta, $5 \mathrm{mg} \cdot \mathrm{L}^{-1}$.

Os valores de coeficiente de variação obtidos na concentração $5 \mathrm{mg} . \mathrm{L}^{-1}$ foram melhores que os de Alves (2014), que realizou validação de um método analítico para a identificação de AGVs em águas intersticiais de sedimentos marinhos por (MEFS/CG/EM), a coluna cromatográfica usada foi a Nukol ${ }^{\mathrm{TM}}$, coluna capilar de sílica fundida de alta polaridade. As concentrações utilizadas para elaborar as curvas de calibração foram entre $1 \mathrm{e}$ $9 \mathrm{mg} \cdot \mathrm{L}^{-1}$ e seus valores de coeficiente de variação foram entre 4,8 para ácido acético, 6,8 para ácido propiônico e 7,7 para ácido butírico. Foram realizados seis ensaios consecutivos.

Zhao et al. (2017) realizaram a extração em fase sólida de fibra embalada acoplada com CG/EM para a determinação de ácidos graxos de cadeia curta na urina infantil, utilizaram uma coluna de alta polaridade, DB-WAX UI MS, obtiveram uma curva de calibração variando de 0,07659 a 765,9 mg. $\mathrm{L}^{-1}$ e seus valores médios dos coeficientes de variação foram, ácido acético, 7,1, ácido propiônico, 7,1, ácido isobutírico, 5,1, ácido butírico, 3,2, ácido isovalérico, 6,6, ácido valérico, 3,0, foram realizados 5 ensaios consecutivos. Para ácido acético o método aqui apresentado se mostrou mais preciso.

Gardana, Del Bo e Simonetti (2017) realizaram validação e aplicação de um método cromatográfico líquido de alta eficiência - Orbitrap espectrométrico de massa para a detecção e quantificação simultânea de ácidos orgânicos voláteis e não voláteis em amostras fecais humanas, com uma coluna $1.8 \mathrm{~m}$ HSS T3, a faixa linear utilizada foi aproximadamente $0,498 \mathrm{mg} \cdot \mathrm{L}^{-1}-18,9 \mathrm{mg} .^{\mathrm{L}-1}$, obtiveram os seguintes valores de coeficiente de variação para precisão do método com relação a repetitividade, ácido acético $(4,7$ - 6,2), ácido propiônico $(2,4-6,9)$, ácido isobutírico $(3,4-5,1)$, ácido butírico (2,3 - 6,2), ácido isovalérico (4,3 - 5,7), ácido valérico $(4,6-4,7)$. As concentrações foram próximas às obtidas pelas maiores concentrações do método em estudo.

\subsubsection{Sensibilidade}

Os cálculos apresentados na tabela 8 mostram excelente capacidade do método aqui validado em determinar concentrações muito próximas de um analito, devido a ter apresentado elevada sensibilidade como verificada pelos altos coeficientes angulares obtidos a partir das curvas de calibração. 
Tabela 8 - Coeficientes angulares dos ácidos graxos voláteis.

\begin{tabular}{|c|c|}
\hline Analito & Coeficientes angulares \\
\hline Ácido acético & 3000000 \\
\hline Ácido propiônico & 1000000 \\
\hline Ácido isobutírico & 420110 \\
\hline Ácido butírico & 238218 \\
\hline Ácido isovalérico & 9000000 \\
\hline Ácido valérico & 5000000 \\
\hline
\end{tabular}

O método se mostrou mais sensível para o ácido isovalérico e menos sensível para o ácido butírico, o que o torna desfavorecido comparativamente quanto a sua detecção e quantificação em relação aos demais ácidos.

Alves (2014) obteve valores de coeficientes angulares para ácido acético, 7854,9, ácido propiônico, 17833 e ácido butírico, 90728 . O presente método apresentou maior sensibilidade para os ácidos citados.

Mesquita et al. (2013) apresentaram dados de validação de uma metodologia para análise de uma mistura de sete ácidos graxos voláteis ( 1 1 a C5) em amostras ambientais por cromatografia líquida de alta eficiência, utilizaram uma coluna de troca iônica HPX-87H , o detector foi UV-Vis com arranjo de diodos, sua faixa de trabalho foi de $12,5 \mathrm{mg} \cdot \mathrm{L}^{-1}$ a $400 \mathrm{mg}^{\mathrm{L}} \mathrm{L}^{-1}$. Os valores de coeficiente angular obtidos foram ácido acético, 1,89, ácido propiônico, 1,76, ácido isobutírico, 2,30, ácido butírico, 1,72, ácido isovalérico 1,77 , ácido valérico 1,49 , valores muito inferiores aos valores de coeficiente angular obtidos pelo método em estudo o que evidencia a vantagem de utilizar como detector um espectrômetro de massas, pois possui alta sensibilidade.

\subsubsection{Limite de Detecção (LD)}

A tabela 9 apresenta os limites de detecção para cada ácido calculados de duas maneiras:, a) a partir das curvas de calibração das diluições do analitos (AGVs) aproximadas do suposto limite de quantificação; b) utilizando o ruído da linha de base (considerando aproximadamente três vezes maior).
Tabela 9 - Limites de detecção calculados a partir das curvas de calibração (a) e utilizando o ruído da linha de base (b).

\begin{tabular}{|c|c|c|}
\hline Analito & LD (a) & LD (b) \\
\hline Ácido acético & $0,086 \mathrm{mg} \cdot \mathrm{L}^{-1}$ & $0,030 \mathrm{mg} \cdot \mathrm{L}^{-1}$ \\
\hline Ácido propiônico & $0,244 \mathrm{mg} \cdot \mathrm{L}^{-1}$ & $0,100 \mathrm{mg} \cdot \mathrm{L}^{-1}$ \\
\hline Ácido isobutírico & $0,196 \mathrm{mg} \cdot \mathrm{LL}^{-1}$ & $0,100 \mathrm{mg} \cdot \mathrm{L}^{-1}$ \\
\hline Ácido butírico & $0,848 \mathrm{mg} \cdot \mathrm{L}^{-1}$ & $0,500 \mathrm{mg} \cdot \mathrm{L}^{-1}$ \\
\hline Ácido isovalérico & $0,515 \mathrm{mg} \cdot \mathrm{LL}^{-1}$ & $0,500 \mathrm{mg} \cdot \mathrm{L}^{-1}$ \\
\hline Ácido valérico & $0,335 \mathrm{mg} \cdot \mathrm{L}^{-1}$ & $0,500 \mathrm{mg} \cdot \mathrm{L}^{-1}$ \\
\hline
\end{tabular}

Comparando os dois métodos, os valores se mostraram próximos para o ácido isovalérico e mais distantes para o ácido butírico.

\subsubsection{Limite de Quantificação (LQ)}

A tabela 10 apresenta os limites de quantificação para cada ácido, calculados de duas maneiras diferentes: a) a partir das curvas de calibração das diluições do analitos (AGVs) aproximadas do suposto limite de quantificação; b) utilizando o ruído da linha de base (considerando aproximadamente dez vezes maior).

Tabela 10 - Limites de quantificação (a) calculados a partir das curvas de calibração e (b) utilizando o ruído da linha de base.

\begin{tabular}{|c|c|c|}
\hline Analito & LQ (a) & LQ (b) \\
\hline Ácido acético & $0,289 \mathrm{mg} \cdot \mathrm{L}^{-1}$ & $0,120 \mathrm{mg} \cdot \mathrm{L}^{-1}$ \\
\hline Ácido propiônico & $0,815 \mathrm{mg} \cdot \mathrm{L}^{-1}$ & $0,400 \mathrm{mg} \cdot \mathrm{L}^{-1}$ \\
\hline Ácido isobutírico & $0,654 \mathrm{mg} \cdot \mathrm{L}^{-1}$ & $0,400 \mathrm{mg} \cdot \mathrm{L}^{-1}$ \\
\hline Ácido butírico & $2,827 \mathrm{mg} \cdot \mathrm{L}^{-1}$ & $2 \mathrm{mg} \cdot \mathrm{L}^{-1}$ \\
\hline Ácido isovalérico & $1,71 \mathrm{mg} \cdot \mathrm{L}^{-1}$ & $2 \mathrm{mg} \cdot \mathrm{L}^{-1}$ \\
\hline Ácido valérico & $1,11 \mathrm{mg} \cdot \mathrm{L}^{-1}$ & $2 \mathrm{mg} \cdot \mathrm{L}^{-1}$ \\
\hline
\end{tabular}

Comparando os dois métodos os valores se mostraram mais próximos para o ácido isovalérico e mais distantes para o ácido butírico.

Raposo et al. (2015), que realizaram a harmonização da determinação quantitativa de perfil de ácidos graxos voláteis em amostras de matriz aquosa por injeção direta, utilizaram técnicas de CG e CLAE: Multi-laboratório estudo de validação, foi utilizada uma coluna de alta polaridade (DB-WAX) 
para o GC. Os detectores foram: detector por ionização de chama (FID), para o GC e para o HPLC, índice de refração e condutividade, sua faixa de trabalho foi de $10 \mathrm{mg} \cdot \mathrm{L}^{-1}$ a $1000 \mathrm{mg} \cdot \mathrm{L}^{-1}$. Os valores dos limites de detecção e limites de quantificação obtidos foram para ácido acético (LD: 3,3 mg.L-1 e LQ: $9,0 \mathrm{mg} \cdot \mathrm{L}^{-1}$ ), ácido propiônico (LD: $2,2 \mathrm{mg} \cdot \mathrm{L}^{-1} \mathrm{e}$ LQ: $10,3 \mathrm{mg} \cdot \mathrm{L}^{-1}$ ), ácido isobutírico (LD: $2,9 \mathrm{mg} \cdot \mathrm{L}^{-1} \mathrm{e}$ LQ: $8,3 \mathrm{mg} \cdot \mathrm{L}^{-1}$ ), ácido butírico (LD: $2,1 \mathrm{mg} \cdot \mathrm{L}^{-1} \mathrm{e} \mathrm{LQ}$ : 7,0 mg. $\mathrm{L}^{-1}$ ), ácido isovalérico (LD: $2,2 \mathrm{mg} \cdot \mathrm{L}^{-1} \mathrm{e}$ LQ: $13,1 \mathrm{mg} \cdot \mathrm{L}^{-1}$ ) e ácido valérico (LD: $1,9 \mathrm{mg} \cdot \mathrm{L}^{-1} \mathrm{e}$ LQ: $\left.6,0 \mathrm{mg} \cdot \mathrm{L}^{-1}\right)$. 0 método aqui utilizado se mostrou mais adequado, pois obteve limites de detecção e quantificação mais baixos para todos os ácidos.

Mulat e Feilberg (2015), já citados, obtiveram os seguintes valores para os limites de detecção e limites de quantificação, ácido acético (LD: 0,260 mg. $\mathrm{L}^{-1}$ e LQ: $0,854 \mathrm{mg} \cdot \mathrm{L}^{-1}$ ), ácido propiônico (LD: 0,443 mg. $\mathrm{L}^{-1}$ e LQ: $\left.1,479 \mathrm{mg} \cdot \mathrm{L}^{-1}\right)$, ácido isobutírico (LD: 0,580 mg. $\mathrm{L}^{-1}$ e LQ: $1,935 \mathrm{mg} \cdot \mathrm{L}^{-1}$ ), ácido butírico (LD: 0,519 mg. $\mathrm{L}^{-1}$ e LQ: $1,730 \mathrm{mg} \cdot \mathrm{L}^{-1}$ ), ácido isovalérico (LD: 0,460 mg. $\mathrm{L}^{-1}$ e LQ: $1,536 \mathrm{mg} \cdot \mathrm{L}^{-1}$ ) e ácido valérico (LD: 0,445 mg. $\mathrm{L}^{-1}$ e LQ: $1,483 \mathrm{mg}^{\mathrm{L} \mathrm{L}^{-1}}$ ). $O$ método aqui apresentado se mostrou mais adequado para os ácidos, acético, propiônico, isobutírico e valérico.

Mannion et al. (2016), em seu trabalho de comparação e validação de dois métodos analíticos para a determinação de ácidos graxos voláteis em produtos lácteos por cromatografia em fase gasosa (utilizando uma coluna específica para AGVs, CP FFAP CB capillary column), com detecção de ionização de chama, utilizando a faixa de trabalho (3mg. $\left.\mathrm{L}^{-1}-700 \mathrm{mg} \cdot \mathrm{L}^{-1}\right)$, no método por injeção direta, obtiveram os respectivos valores de limite de detecção e quantificação para o ácido butírico (LD:0,7 mg.L-1 e LQ:3 mg.L-1). Os valores do método aqui utilizado foram predominantemente melhores para o respectivo ácido.

\subsubsection{Exatidão}

A exatidão do método relaciona o valor obtido com o valor teórico das concentrações e foi calculada baseada nas concentrações baixa $\left(0,5 \mathrm{mg} \cdot \mathrm{L}^{-1}\right)$, média ( 2 $\left.\mathrm{mg} \cdot \mathrm{L}^{-1}\right)$ e alta $\left(5 \mathrm{mg} \cdot \mathrm{L}^{-1}\right)$, sendo feitas seis determinações para cada concentração. As tabelas 11, 12, 13 apresentam os valores de exatidão obtidos.

Tabela 11 - Valores de exatidão para a concentração $0,5 \mathrm{mg} \cdot \mathrm{L}^{-1}$.

\begin{tabular}{|c|c|c|}
\hline \multicolumn{1}{|c|}{ Analito } & Exatidão (\%) & Coeficientes de Variação (\%) \\
\hline Ácido acético & 132 & $\pm 5,7$ \\
\hline Ácido propiônico & 130 & $\pm 6,6$ \\
\hline Ácido isobutírico & 126 & $\pm 5,9$ \\
\hline Ácido butírico & 152 & $\pm 7,6$ \\
\hline Ácido isovalérico & 130 & $\pm 3,8$ \\
\hline Ácido valérico & 129 & $\pm 2,8$ \\
\hline
\end{tabular}

Tabela 12 - Valores de exatidão para a concentração $2 \mathrm{mg} \cdot \mathrm{L}^{-1}$.

\begin{tabular}{|c|c|c|}
\hline Analito & Exatidão (\%) & Coeficientes de Variação (\%) \\
\hline Ácido acético & 100 & $\pm 5,2$ \\
\hline Ácido propiônico & 105 & $\pm 8,4$ \\
\hline Ácido isobutírico & 107 & $\pm 7,0$ \\
\hline Ácido butírico & 102 & $\pm 9,0$ \\
\hline Ácido isovalérico & 105 & $\pm 10,2$ \\
\hline Ácido valérico & 100 & $\pm 10,9$ \\
\hline
\end{tabular}

Tabela 13 - Valores de exatidão para a concentração $5 \mathrm{mg} \cdot \mathrm{L}^{-1}$.

\begin{tabular}{|c|c|c|}
\hline Analito & Exatidão (\%) & Coeficientes de Variação (\%) \\
\hline Ácido acético & 108 & $\pm 9,7$ \\
\hline Ácido propiônico & 109 & $\pm 7,4$ \\
\hline Ácido isobutírico & 108 & $\pm 7,2$ \\
\hline Ácido butírico & 110 & $\pm 5,5$ \\
\hline Ácido isovalérico & 107 & $\pm 6,3$ \\
\hline Ácido valérico & 110 & $\pm 7,6$ \\
\hline
\end{tabular}

Analisando os valores de exatidão para cada concentração se observa que o método teve uma boa exatidão para as concentrações $2 \mathrm{mg}^{\mathrm{L}^{-1}}$ e 5 $\mathrm{mg} \cdot \mathrm{L}^{-1}$, pois os valores são satisfatórios para todos os ácidos, considerando que o intervalo de exatidão pode variar de $80 \%$ a $120 \%$ e o coeficiente 
de variação pode variar até $20 \%$ (ANVISA, 2003). Segundo INMETRO (2016), para o intervalo de concentração de $0,1 \mathrm{mg} \cdot \mathrm{L}^{-1}$ a $10 \mathrm{mg} \cdot \mathrm{L}^{-1}$, aceita-se a recuperação na faixa de $80 \%$ a $110 \%$, enquadrando-se dentro desse intervalo todos os ácidos das concentrações $2 \mathrm{mg} \cdot \mathrm{L}^{-1}$ e $5 \mathrm{mg} \cdot \mathrm{L}^{-1}$. O método não apresentou boa exatidão para a concentração $0,5 \mathrm{mg} \cdot \mathrm{L}^{-1}$.

Zhou et al. (2016) realizaram determinação rápida de ácidos fórmico e acético em biomassa hidrolisada utilizando cromatografia gasosa com headspace e um detector de ionização de chama (FID). As separações cromatográficas foram realizadas com coluna capilar de sílica fundida HP-5 (30 m de espessura de 0,32 $\mathrm{mm}$ de diâmetro $0,25 \mathrm{~mm}$ de espessura) e uma coluna capilar de sílica HP-INNOWax (30 m 0,25 mm de diâmetro 0,25 mm de espessura de película). Obtiveram-se curvas de calibração na gama de 5 a 16000 mg.L L $^{-1}$ e valores de exatidão para ácido acético (97\% - 103\%), sendo estes bem próximos aos obtidos no presente trabalho; todos estão dentro do intervalo aceito.

Cerqueira et al. (2011), na validação do método para a determinação de ácidos graxos voláteis (acético, propiônico e butírico) por HPLC-DAD em efluentes de reatores anaeróbios tratando esgotos domésticos e utilizando coluna c18, com faixa trabalho de $7,5 \mathrm{mg} \cdot \mathrm{LL}^{-1}$ a $300 \mathrm{mg} \cdot \mathrm{L}^{-1}$, obtiveram valores de exatidão para ácido acético $(98 \%$ - 100\%), ácido propiônico (90,1\% - 102\%), ácido butírico (89,6\% - 99,2\%), valores próximos aos aqui encontrados.

A validação do método para todos os parâmetros se mostrou adequada e viável, pois a maior parte das concentrações utilizadas atendeu aos critérios estabelecidos pela ANVISA (2003) e INMETRO (2016); se comparada a literatura, os valores foram bem próximos para trabalhos com CG, CLAE, utilizando diversos detectores. As análises foram realizadas de forma simples e econômica, por injeção direta, não utilizando algumas técnicas mostradas em alguns trabalhos citados, como headspace, micro extração em fase sólida e derivatização. A coluna utilizada para determinação de AGVs não foi específica, sua polaridade era intermediária, o que pode ter contribuído, para em alguns casos a concentração mais baixa da faixa de trabalho, que foi $0,5 \mathrm{mg} \cdot \mathrm{L}^{-1}$, ter ficado fora dos critérios de validação estabelecidos, na precisão a concentração de $0,5 \mathrm{mg} . \mathrm{L}^{-1}$, não obedeceu ao critério do INMETRO (2016) e na exatidão essa concentração não obedeceu aos critérios ANVISA (2003) e INMETRO (2016), pode ter contribuído também para a deficiência do ácido isobutírico e butírico com relação a linearidade em relação aos outros ácidos, pois ficou fora do critério ANVISA (2003), na sensibilidade o ácido butírico ficou desfavorecido em relação aos outros ácidos e também apresentou o maior limite de detecção, mesmo com pequenas limitações, os resultados foram em sua maioria satisfatórios e o método foi devidamente validado.

\subsubsection{Aplicação do Método em Matrizes Reais}

A eficácia do método CG/EM validado sob as condições definidas foi determinada a partir da medição da concentração de AGVs utilizando amostras reais de lodos de reatores anaeróbios e do permeado de um biorreator anaeróbio de membrana dinâmica, alimentados com lodo de descarte de um sistema de lodo ativado e efluente proveniente de uma biorreator anaeróbio de batelada, alimentado com resíduos sólidos. Foram escolhidas amostras aleatórias de lodo e permeado (BRAn$M D$ ), lodo efluente (DAC1), lodo (DAC 2) e efluente (resíduos sólidos), para comparar seus tempos de retenção com os tempos de retenção dos padrões, para avaliar o efeito de matriz. 
Tabela 14 - Concentração, tempos de retenção das amostras e tempos de retenção dos padrões.

\begin{tabular}{|c|c|c|c|c|c|c|c|}
\hline Amostras & - & Acético & Propiônico & Isobutírico & Butírico & Isovalérico & Valérico \\
\hline $\begin{array}{l}\text { Tempo de retenção do } \\
\text { padrão (min) }\end{array}$ & - & 5,81 & 6,89 & 7,51 & 7,81 & 8,35 & 8,73 \\
\hline \multirow{2}{*}{ Lodo (BRAnMD) } & $\begin{array}{c}\mathrm{C} \\
\left(\mathrm{mg} \cdot \mathrm{L}^{-1}\right)\end{array}$ & 23,64 & 60,48 & 209,16 & 109,88 & 12,32 & 22,72 \\
\hline & $\begin{array}{c}\text { Tra } \\
\text { (min) }\end{array}$ & 5,33 & 6,58 & 6,88 & 7,21 & 7,83 & 7,92 \\
\hline \multirow{2}{*}{ Permeado (BRAnMD) } & $\begin{array}{c}\mathrm{C} \\
\left(\mathrm{mg} \cdot \mathrm{L}^{-1}\right)\end{array}$ & 25,28 & 74,56 & 217,44 & 131,8 & 12,36 & 22,76 \\
\hline & $\begin{array}{l}\text { Tra } \\
\text { (min) }\end{array}$ & 5,38 & 6,57 & 6,87 & 7,20 & 7,82 & 7,94 \\
\hline \multirow{2}{*}{$\begin{array}{l}\text { Lodo } \\
\text { efluente (DAC1) }\end{array}$} & $\frac{\mathrm{C}}{\left(\mathrm{mg} \cdot \mathrm{L}^{-1}\right)}$ & 25,68 & 81,72 & 255,72 & 140,72 & 12,32 & 22,64 \\
\hline & $\begin{array}{l}\text { Tra } \\
\text { (min) }\end{array}$ & 5,36 & 6,57 & 6,87 & 7,20 & 7,83 & 7,92 \\
\hline \multirow{2}{*}{$\begin{array}{l}\text { Lodo } \\
\text { (DAC 2) }\end{array}$} & $\frac{\mathrm{C}}{\left(\mathrm{mg} \cdot \mathrm{L}^{-1}\right)}$ & 25,48 & 82,64 & 157,96 & 196,68 & 12,28 & 22,68 \\
\hline & $\begin{array}{c}\text { Tra } \\
\text { (min) }\end{array}$ & 5,38 & 6,58 & 6,87 & 7,20 & 7,82 & 7,92 \\
\hline \multirow{2}{*}{$\begin{array}{c}\text { Efluente } \\
\text { (Resíduos sólidos) }\end{array}$} & $\underset{\left(m g \cdot L^{-1}\right)}{C}$ & 16,75 & 8,95 & 30,25 & 271 & 5,65 & 20,05 \\
\hline & $\begin{array}{l}\text { Tra } \\
\text { (min) }\end{array}$ & 5,53 & 6,68 & 7,03 & 7,43 & 7,63 & 7,71 \\
\hline
\end{tabular}

C = concentração; Tra = tempo de retenção da amostra.

Os tempos de retenção das amostras e dos padrões foram muito próximos, indicando que o efeito matriz não foi significativo e levando em consideração que pode haver variação do tempo de retenção de acordo com a variação da concentração da amostra. A aplicação do método validado em matrizes reais foi satisfatória.

\section{CONCLUSÃO}

A validação do método de cromatografia gasosa usando como detector um espectrômetro de massas foi fundamental para sua credibilidade, assegurando a confiança dos seus resultados, de acordo com ANVISA e INMETRO. O método se mostrou viável para determinação de ácidos graxos voláteis (ácido acético, ácido propiônico, ácido isobutírico, ácido butírico, ácido isovalérico, e ácido valérico), pois atendeu aos parâmetros de validação (linearidade, precisão, sensibilidade, limite de detecção, limite de quantificação e exatidão), principalmente nas concentrações mais elevadas da faixa de trabaIho. Quando aplicado em matrizes reais, ficou comprovada a sua eficácia, tendo em vista que os tempos de retenção dos ácidos presentes nas matrizes reais foram bem próximos aos tempos de retenção dos ácidos nos padrões. Destaca-se que as análises foram realizadas por injeção direta, de forma simples e econômica e foi utilizada uma coluna de polaridade média, com as vantagens de seu baixo custo e de não ser exclusiva para a detecção e quantificação de AGVs, obtendo-se excelentes resultados.

\section{REFERÊNCIAS}

AGÊNCIA NACIONAL DE VIGILÂNCIA SANITÁRIA (ANVISA). Resolução RE n 899 de 29 de maio de 2003. Guia para validação de métodos analíticos e bioanalíticos. Diário Oficial da República Federativa do Brasil. Brasília, DF.

ALEM SOBRINHO, P. Tratamento de esgoto e produção de lodo. In: Biossólidos na agricultura. São Paulo: SABESP, 2001. p. 7 - 40.

ALVES, S. I. C. Validação de um método analítico para a identificação de ácidos gordos voláteis em águas intersticiais de sedimentos marinhos por SPME-GC-MS. LISBOA, 2014. 58f. Dissertação (Mestrado em Química) - UNIVERSIDADE DE LISBOA, 2014.

AMER, B. et al. Novel method for individual free fatty acids in milk using an in- solution derivatisation approach and gas chromatography - mass spectrometry. International Dairy jornal, v. 32, p. $199-2003,2013$.

ANDREOLI, C. V., VON SPERLING, M., FERNANDES, F. Lodo de esgoto: Tratamento e disposição final. Rio de Janeiro: Editora ABES, 2001. 483 p. 
AOAC International., Official methods of analysis of AOAC International, in Guidelines for Standard Method Performance Requirements (Appendix F). Gaithersburg: AOAC International, 2012.

BRASIL. Conselho Nacional do Meio Ambiente. Resolução n 430 , 13 de Maio de 2011. Dispõe sobre as condições e padrões de lançamento de efluentes, complementa e altera a Resolução $n^{\circ} 357$, de 17 de março de 2005, do Conselho Nacional do Meio Ambiente - CONAMA. DOU n 92 de 16 maio, 2011, pág. 89.

BRASIL. Lei n 12.305 - Institui a Política Nacional de Resíduos Sólidos. Brasília - Distrito Federal, 2010.

CERQQUEIRA, M. B. R. et al. Validação de método para determinação de ácidos orgânicos voláteis em efluentes de reatores anaeróbios empregando cromatografia líquida. Química Nova, v. 34, n. 1, p. 156-159. 2011.

CHAGAS, W.F. Estudo de patógenos e metais em lodo digerido bruto e higienizado para fins agrícolas, das estações de tratamento de esgotos da ilha do governador e da Penha no estado do Rio de Janeiro. (Mestrado) Fundação Oswaldo Cruz, Escola Nacional de Saúde Pública; 2000. 89 p.

CHERNICHARO, C.A.L. Princípios do Tratamento Biológico de Águas Residuárias . Vol. 5 , Reatores Anaeróbios. Belo Horizonte: Segrac, 1997.

CORVINI, P.F.X.; SCHAFFER, A.; SCHIOSSER, D. Microbial biodegradation of nonylphenolando the ralkyl phenols. App. Microbial Biotechnol.Germany, v 72, p. 223 -243.Apr/Jun 2006.

EURACHEM Guide: The Fitness for Purpose of Analytical Methods - A Laboratory Guide to Method Validation and Related Topics. Magnusson, B. and U. Örnemark (Ed.), 2014.

FIORINI, D. et al. A quantitative headspace - solid - phase microextraction - chromatography - flame ionization detector method to analyze short chain free acids in rat faces. Analytical Biochemistry, v. 508, p. 12-14, June, 2016.

GARDANA, V.; BO, C. D.; SIMONETTI, P. Validation and application of na ultrahigh-performance liquid chromatographic - Orbitrap mass spectrometic method for the simultaneous detection and quantification of volatile and non-volatile organic acids in human faecal samples. Journal of pharmaceutical and Biomedical Analysis, v. 141, p. 46-51, July, 2017.

INSTITUTO NACIONAL DE METROLOGIA, NORMALIZAÇÃO EQUALIDADE INDUSTRIAL (INMETRO). Orientação sobre validação de métodos analíticos. Documento orientativo DOQCGCRE-008. p. 35. 05 ago. 2016.

JONSSON, C.M.; MAIA, C.H.M. Avaliação da toxicidade do lodo de esgotos de duas estações de tratamento de esgotos para o invertebrado aquático Daphniasimilis. Pesticida: r-ecotoxicol e Meio Ambiente, v17, página 1 - 8. Jan/Dez 2007.

LEITÃO, R.C.; VAN HAANDEL, A.C.; ZEEMAN G.; LETTINGA, G. The effects of operational and environmental variations on anaerobic wastewater treatment systems: A review. Bioresource Technology,v 97 (2006). P. 1105-1118.
LETTINGA, G., HULSHOFF POL, L.W.H., ZEEMAN, G. Biological Wastewater Treatment Part1 Anaerobic Wastewater Treatment. Wageningen University, Wageningen, The Netherlands, p. 200. 2000.

MADIGAN, M.T.; MARTINKO, J.M.; BENDER, K.S.; BUCKLEY, D.H.;STAHL, D.A. Microbiologia de Brock. Artmed, 14 Ed. 960 p. 2016.

MAGALHÃES, M. N.; LIMA, A. C. P. Noções de Probabilidade e Estatística. 6 ed. Editora da Universidade de São Paulo, 2004.

MANNION, D. et al. Comparison and validation of 2 analytical methods for the determination of free fatty acids in dairy products by gas chromatography with flame ionization detection. Jounal of Dairy Science, v. 99, n. 7, p. 1-17, 2016.

MESQUUTA, P. L. et al. Validação de método de cromatografia líquida para a determinação de sete ácidos graxos voláteis intermediários da digestão anaeróbia. Eng Sanit Ambient, v.18, n.4, p. 295-302, out/dez. 2013

METCALF, L.; EDDY,H. P. Wastewater Engineering. Treatment and Reuse. McGraw Hill, 4ed. 2003. 1927 p.

MIKI, M. K.; ALEM SOBRINHO, P.; VAN HAANDEL, A. C. Tratamento da fase sólida em estações de tratamento de esgotos - condicionamento, desaguamento mecanizado e secagem térmica do lodo. In: Biossólidos: Alternativas de Uso de Resíduos do Saneamento. Rio de Janeiro: ABES, 2006.

MULAT, D.G.; FEILBERG,A. GC/MS method for determining carbon isotope enrichment and concentration of underivatized short-chain fatty acids by direct aqueous solution injection of biogas digester samples. Talanta. 2015.

RAPOSO, F. et. al. Harmonization of the quantitative determination of volatile fatty acids profile in aqueous matrix samples by direct injection using GC and HPLC techniques: Multi-laboratory validation study. Journal of Chromatography. Agosto, 2015.

SAWYER, C. N.; MCCARTY, P. L. Chemistry for Environmental Engineering. 3ed. McGrawHill Book Company, 1978.

SOARES, M. R. (2004). Coeficiente de distribuição (kd) de metais pesados em solos do estado de São Paulo. 2004. 202p. (Doutorado) - Universidade de São Paulo. São Paulo: 2004.

TYAGI, V. K.; LO, S-L.Sludge: A waste or renewable source for energy and resources recovery? Renewable and Sustainable Energy Reviews, n. 25, p. 708-728, 2013.

VAN HAANDEL, A. C., LETTINGA, G. Tratamento Anaeróbio de Esgotos: Um Manual para Regiões de Clima Quente, Epgraf, Campina Grande, 240 p, 1994.

ZHAO, R. et al. Application of packed - fiber solid - phase extraction coupled with GC-MS forthe determination of short - chain fatty acids in children's urine. China ChinaActa. v. 468, p. 120125, February, 2017.

ZHOU, D. et al. Rapid determination of formic and acetic acids in biomass hydrolysate by headspoce gas chromatography. Journal of Industrial and Engineering chemistry. November, 2016. 


\section{ANEXOS}

Curvas de calibração e gráfico de resíduos, dos ácidos analisados:
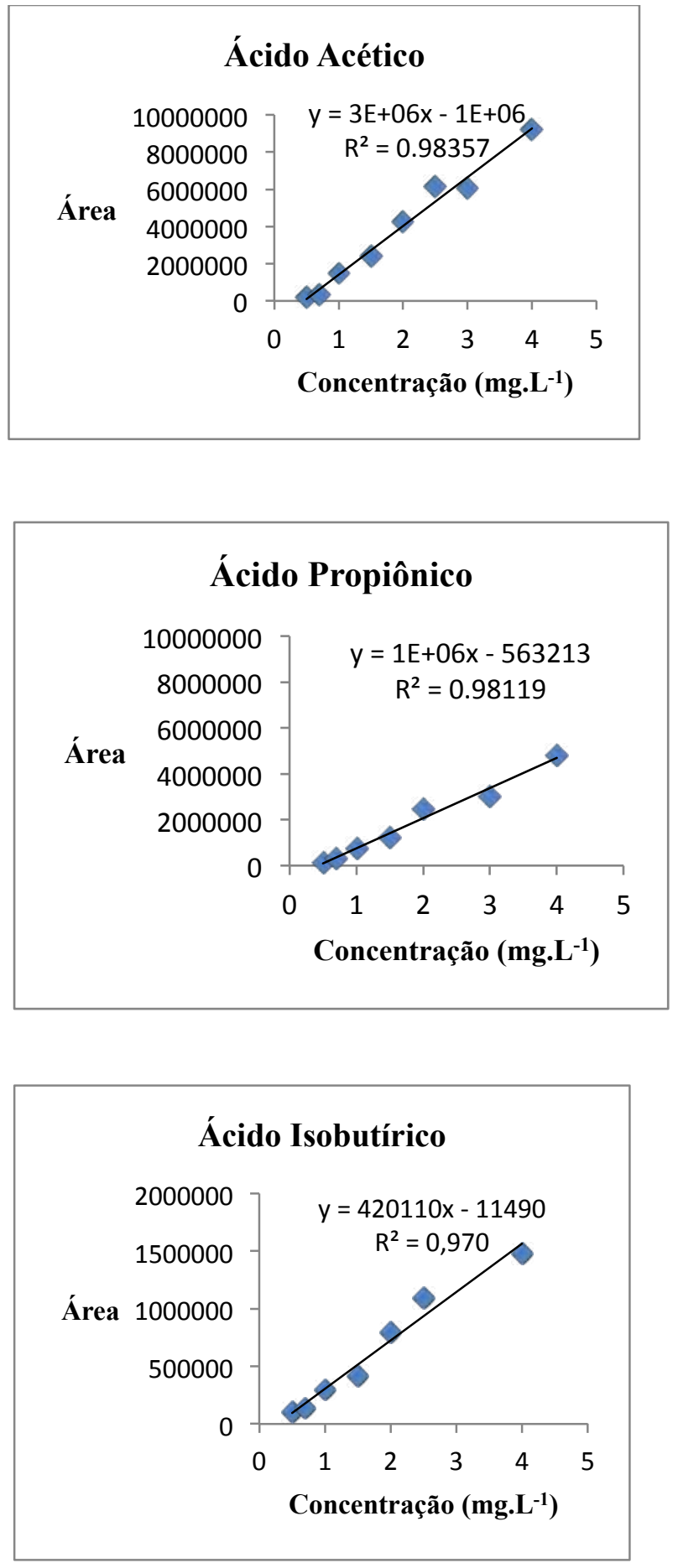
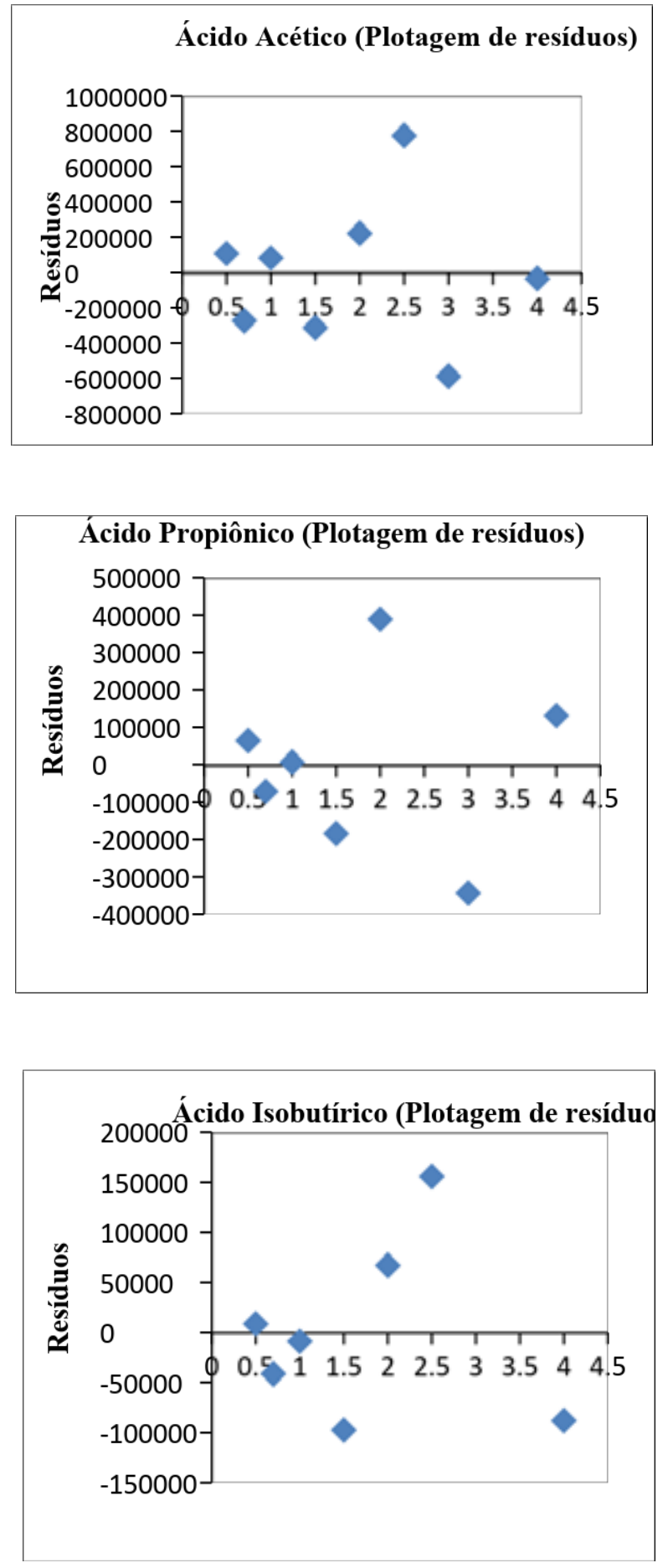


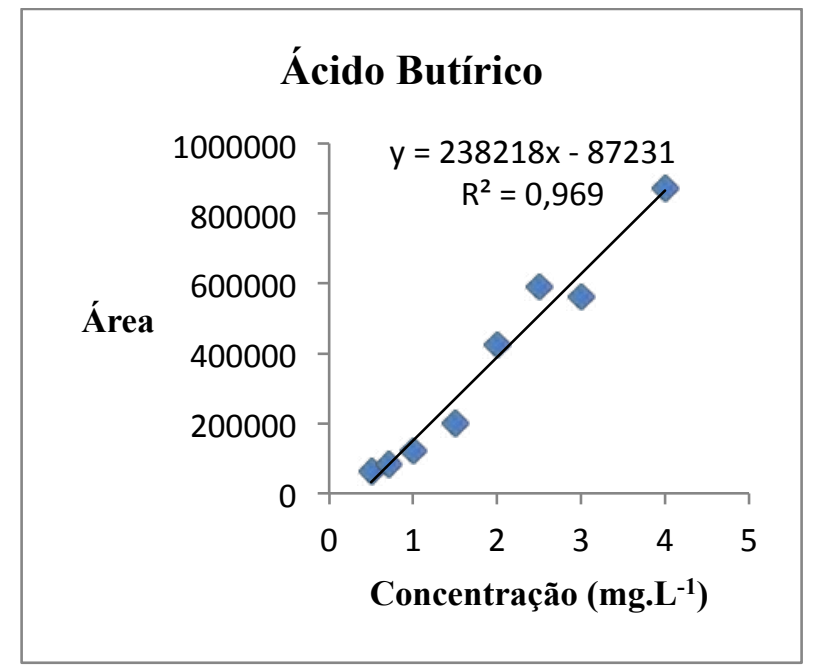

\section{Ácido Isovalérico}

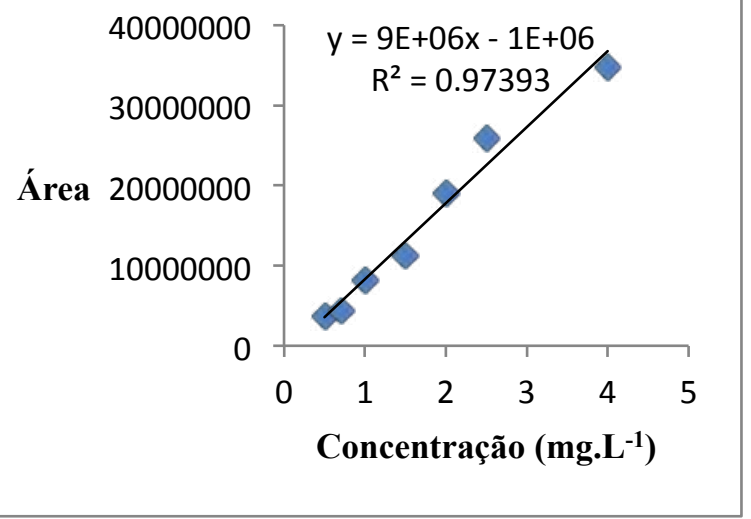

\section{Ácido Valérico}

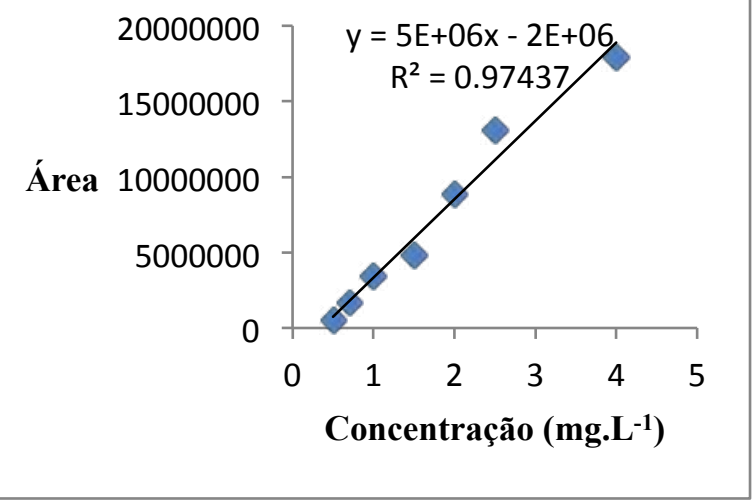

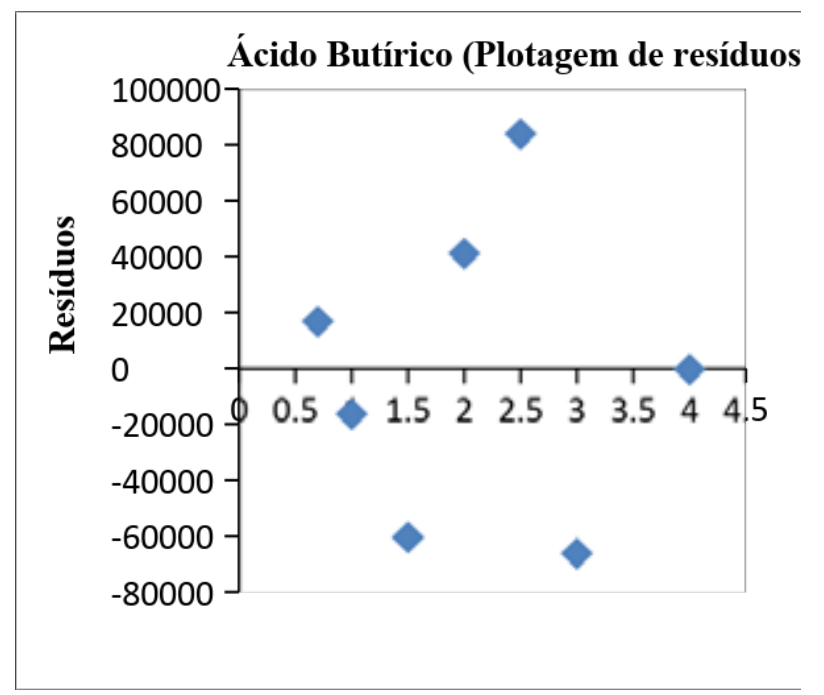
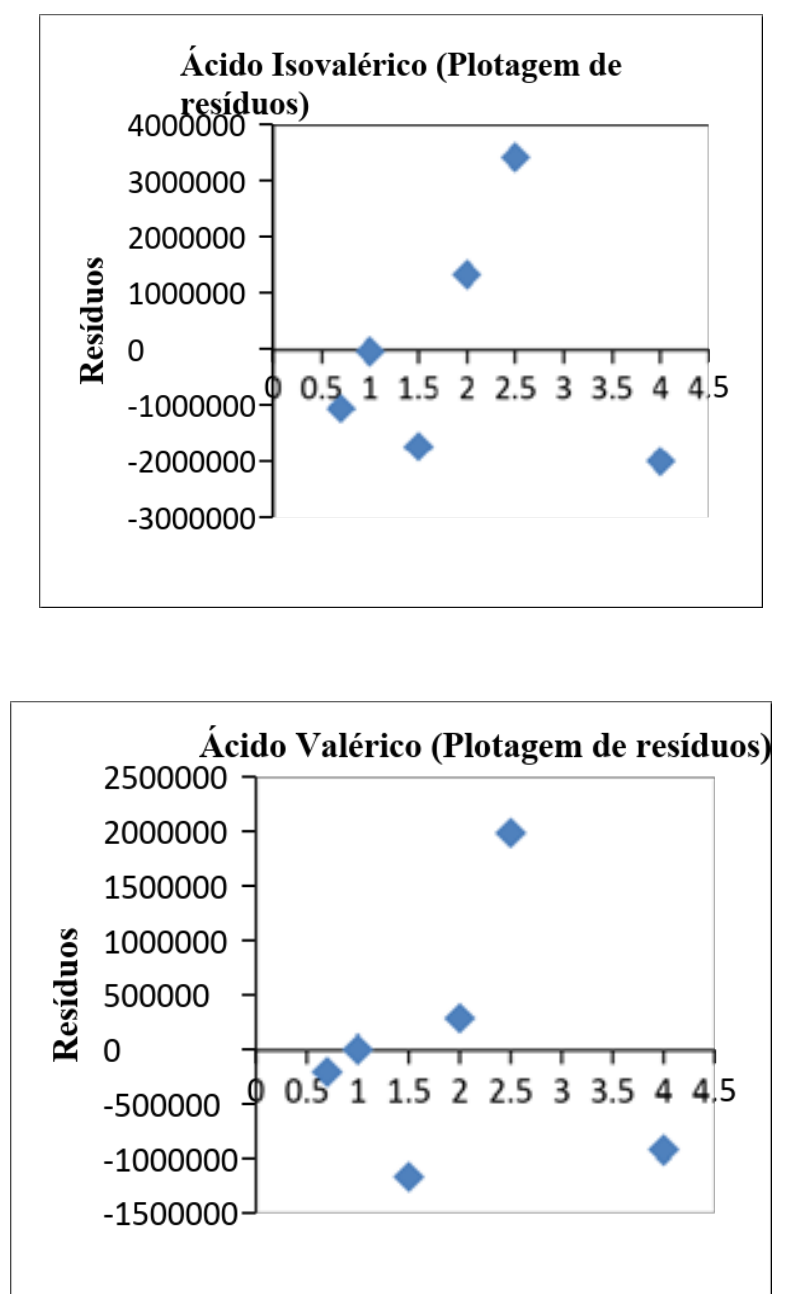